somewhat fluorescent, for they are easily visible in poor lighting, even with coloured solutions. Furthermore, the markings, which are fused into the glass, seem to be irremovable except by such chemicals as those which corrode the glass itself.

Stoppers in graduated flasks and cylinders have always tended to be troublesome owing to a profensity for 'seizing'. The new 'E-MIL' stopper is a valuable accessory. Accurately moulded from an almost inert plastic, it provides a gas-tight and liquid-tight closure to an orifice of British Standards Institution specification taper (although it is not of B.S.I. specification dimensions), but does not bind or seize up irremovably. It is understood that patent protection is being sought for this attractive article.

Nor is this all, for the firm has introduced another innovation. It feels that the old style of crating a number of items amid masses of wood-wool, straw, sawdust and the like is not good enough for precision equipment; the packing material might be dusty and soil the articles, even if paper wrappings are used in addition, and by no means does it ensure safe transport unless an expert is employed to pack and another to unpack. Even with this system, overhead costs can easily be inflated by 'on-the-floor' losses in transferring the goods to storage bins, then to shelves and counters and finally with, or sometimes without, further packing, to the possession of the ultimate user. The firm feels that it can reduce these losses by sealing each article into its own specially fitting carton, which will be unreturnable and will doubtless be retained by many a technician as it provides a convenient pigeon-hole for the safe storage of the article in his locker. It is obvious that the extra expenses of this carton packing will be offset by dispensing with crates, etc., and with the trouble of their recovery as returned empties, not forgetting the overhead expenses and office work associated with the latter.

This programme could not be so courageously planned by the management had it not the wholehearted loyalty of its employees, to whom it gives very strong incentives to produce not only quantity but also quality in whatever they are making. The result is not a mere 'master and man' condition but the development of what may be described as a happy family, some members of which are miners who can no longer follow their former employment because of the dreaded silicosis, some are ex-Service men whose injuries limit their capabilities in the way of earning a living, and others are women and young people with a flair for delicate manipulation. It is good to see them working with a will, and everywhere there is evidence-sometimes resonant-of happy and contented folk.

R. SuTCLIFE

\section{EDUCATION IN HAITI}

$\mathrm{T}$ HE U.S. Office of Education has undertaken the preparation of a series of basic studies in education in a number of Central and South American countries. This series of studies is part of a programme to promote understanding of educational conditions in the American countries and to encourage co-operation in the field of inter-American education. The project, part of a government-wide programme of cultural co-operation under the auspices of the
U.S. Department of State, was begun in the autumn of 1943. It involves travel by Office of Education specialists in the various countries in order to gather information at first hand on their educational systems and to prepare reports for publication.

"Education in Haiti" (Washington, D.C. : Gov. Printing Office. 25 cents) is based on data collected by Prof. Mercer Cook during a twenty-two months stay in which, as supervisor of an English-teaching project which was initially sponsored by the U.S. Office of Education, he was able to make use of authoritative sources of information.

The total area of the Republic of Haiti is about 10,700 square miles, more than two-thirds of which is covered by highlands. This complicates the construction of roads and renders many villages practically inaccessible to commerce and to education. The high rate of illiteracy-estimated at about 92 per cent by some observers-should thus be attributed in some part to topography. No scientific attempt has ever been made to count the total number of Haitians, but an estimate made in 1937 puts the total population at about three millions. Of these, nine-tenths live in rural areas and, as in other LatinAmerican countries, the fundamental educational problem is that of the rural school. Already, in the words of a contemporary Haitian novelist, erosion has "bled the earth to the bone", and the problem of this agricultural country is to try to intensify its agricultural effort by educating the peasant in modern methods of cultivation and soil conservation. Until this problem of rural education is satisfactorily solved, Haiti seems destined to remain a desperately poor country. The converse is equally true. Progress has been made in recent years; but the deplorable facts remain that four out of five peasant children never attend school ; that teachers' salaries are inadequate; that many school buildings are hopelessly unsatisfactory; that equipment and textbooks are often unobtainable; that malaria, yows, syphilis, tuberculosis and hookworm have undermined the health of the Haitian; that, as one Haitian physician states, "the diet of the Haitian peasant has not changed since slavery days"; and that education has been tied up too closely with politics.

The language problem is also a considerable source of difficulty to Haitian educationists. The official language of the republic is French, while "not one peasant out of a 100 can even guess what is being said in that language"; all Haitians understand Creole and most of them speak it. From Prof. Cook's observations it is apparent that poverty, ill-health, polities and linguisties are the basic ills that beset the Haitian school teacher, and the greatest of these is poverty. "On less than the average income of a first-class American university, the Haitians must provide and maintain elementary, secondary, professional, rural and vocational schools for a population of approximately three millions."

Despite these and other obstacles, however, the Haitians, through their own efforts and with some aid from foreigners, principally French and North American, have, during the last twenty years, progressed along the road to enlightenment. Their schools are no longer entirely literary or classical, teachers are better trained and somewhat better paid; printed regulations are less frequently disregarded. Yet, as Prof. Cook has shown, much remains to be done, and his report will prove invaluable in concentrating attention on the state of education in Haiti.
T. H. HawkINS 